\title{
Estructura floral de dos especies de Trachycarpeae (Arecaceae)
}

\author{
Lorena I. Guevara ${ }^{1}$, Damelis J. Jáuregui ${ }^{1} \&$ Fred W. Stauffer ${ }^{2}$
}

1. Instituto de Botánica Agrícola Facultad de Agronomía, Universidad Central de Venezuela, apartado postal 4579, Maracay 2101, Aragua, Venezuela; loisag@gmail.com, jaureguid@gmail.com

2. Conservatoire et Jardin botaniques de la Ville de Genève, Université de Genève, Ch. de l'Impératrice 1, case postale 60,1292 Chambésy/ Geneva, Switzerland; fred.stauffer@ville-ge.ch

$$
\text { Recibido 26-IX-2013. Corregido 15-I-2014. Aceptado 13-II-2014. }
$$

\begin{abstract}
Floral structure of two species of Trachycarpeae (Arecaceae). Copernicia and Washingtonia are two genera of the Trachycarpeae for which no subtribal classification has been proposed, mainly because of the lack of resolution in phylogenetic studies. Morphology and anatomy of flowers whithin Coryphoideae have proven useful for taxa delimitation and supporting relationships among their members. A description of the morphological and anatomical structure of flowers of C. tectorum and W. filifera is presented in order to explore reproductive characters that may clarify their classification within the subfamily and to contribute with floral biology studies. Flowers of cultivated specimens of both taxa and developing fruits of C. tectorum were fixed in FAA, dissected for morphological analysis, and parafin-embedded flowers and fruits were serially sectioned for obtaining permanent slides, using conventional techniques and safranin-fast green staining. All procedures were carried out in the Laboratory of Morpho-Anatomy, Agronomy Faculty of the Universidad Central de Venezuela (UCV). Both species have hermaphroditic flowers. C. tectorum flowers have a thick and pubescent perianth, six stamens with filaments forming a tube fused to the corolla, with rounded projections and an acute apex where the anthers are inserted. $W$. filifera flowers have an irregularly dentate calyx, and a shortly acuminate corolla, six stamens united by their filaments to the corolla which at the same time are briefly fused to the gynoecium. Cells with druse crystals in the staminal tube are reported for $C$. tectorum. Only one of the carpels of the gynoecium of $C$. tectorum develops at fruit stage, and a layer of abundant raphide cells forming a crustaceous endocarp in mature fruits, was found. $W$. filifera presents the perianth mesophyll with few layers of thick walled cells and schlerenchymatic tissue, gynoecium with apically fused carpels in the ventral region of ovary, free at the base and the apex of the style, where the ventral sutures are opened. C. tectorum has a ventral hypodermis in the petals made of large and thick walled cells, gynoecium with apically fused carpels in the ovary, free and adpressed basally, style-stigma completely fused, and stylar transmission channel absent distally. Distinct stylar canals in $C$. tectorum, united distally in $W$. filifera confirm the close relationship between these species and subtribe Livistoninae. Also, some floral morpho-anatomical similarities (e.g. fleshy calyx base and a hypodermis with thickened cell walls in petals) were found between C. tectorum and Pritchardia, supporting the affinities between both genera. Rev. Biol. Trop. 62 (3): 1137-1146. Epub 2014 September 01.
\end{abstract}

Key words: anatomy, Arecaceae, Copernicia tectorum, flowers, morphology, Trachycarpeae, Washingtonia filifera.

La tribu pantropical Trachycarpeae (subfamilia Coryphoideae) contiene géneros principalmente neotropicales que no han sido ubicados en subtribus por la carencia de resolución en los estudios filogenéticos (Dransfield et al., 2008). Dos de estos géneros, Copernicia Mart. ex Endl. y Washingtonia $\mathrm{H}$. Wendl., poseen una taxonomía complicada, dificultándose la identificación de sus especies (Henderson, Galeano, \& Bernal, 1995). En el último análisis filogenético para las subfamilias de Arecaceae, Baker et al. (2009) utilizaron gran cantidad de evidencia molecular y morfológica, y no lograron resolver dos de las tribus más grandes, Areceae (Arecoideae) y Trachycarpeae (Coryphoideae), señalando que 
esto se puede alcanzar reuniendo más datos de diversa índole sobre los géneros. En cuanto a las posibles relaciones entre estos géneros, el estudio filogenético más reciente de Trachycarpeae, confirma la cercanía en las relaciones entre Pritchardia, Corpernicia y Washingtonia (Bacon, Baker, \& Simmons, 2012).

En la familia Arecaceae son conocidos los trabajos morfológicos $\mathrm{y}$ anatómicos de desarrollo floral con fines taxonómicos (Baker, Dransfield, Harley, \& Bruneau, 1999; Kahn \& Gluchy, 2002; Stauffer, Rutishauser, \& Endress, 2002; Stauffer \& Endress, 2003; Rudall, Abranson, Dransfield, \& Baker, 2003). Dentro de la subfamilia Coryphoideae se ha utilizado la morfo-anatomía de los órganos reproductivos para explicar entre otras cosas, relaciones filogenéticas y aspectos de la biología reproductiva. Esto se ve reflejado en el trabajo de Uhl, Morrow, y Moore (1969) quienes describieron la anatomía de flores de Rhapis excelsa (Thunb.) Henry, determinando la placentación laminar del óvulo, relacionada con la derivación múltiple de trazas hacia el óvulo desde la región dorsal. En el gineceo de las Coryphoideae, Uhl y Moore (1971) realizaron dos agrupaciones de géneros unicarpelares basados en la extensión de los haces vasculares ventrales estigmáticos. Giddey, Spichiger, y Stauffer (2009) sugirieron la división de las especies de Rhapis en dos grupos basados en caracteres de los filamentos estaminales y resaltaron la necesidad de nuevas investigaciones sobre las flores de algunos géneros dentro de Coryphoideae para lograr comparaciones más detalladas. Castaño, Crèvecoeur, y Stauffer (2009) determinaron que los tres carpelos en el gineceo de Sabal palmetto (Walter) Lodd. ex Schult. estan libres en la base, apoyando las relaciones entre Sabal y Cryosophileae. Las relaciones internas de esta tribu fueron estudiadas en detalle por Castaño, Crèvecoeur, Pintaud, y Stauffer (2011). Rudall, Ryder, y Baker (2011) determinaron cuatro tipos de gineceo dentro de las Coryphoideae según el número y grado de fusión de sus carpelos.

Copernicia tectorum (Kunth) Mart. (palma llanera) es un elemento sobresaliente en los llanos centrales venezolanos y orientales colombianos; formando además en Venezuela, comunidades en ambas riberas del Lago de Maracaibo (Huber \& Oliveira-Miranda, 2010). Washingtonia filifera (Linden ex André) $\mathrm{H}$. Wendl. ex de Bari (palma del desierto, o palma de abanico de California) es plantada ampliamente como ornamental en zonas tropicales y subtropicales del mundo y se distribuye desde el sureste de California y oeste de Arizona en Estados Unidos hasta el noroeste de México (Henderson et al., 1995). A pesar de la utilidad que muestran los estudios mencionados, las investigaciones detalladas sobre la estructura morfológica y anatómica de flores en Coryphoideae siguen siendo escasas, por lo que en este trabajo se presenta la descripción de la morfo-anatomía de las flores de C. tectorum y $W$. filifera con la finalidad de: (1) aportar información para la sistemática de las Coryphoideae, en especial para la ubicación de estos dos géneros dentro de subtribus en Trachycarpeae y (2) contribuir con información básica para los estudios de biología floral en esta subfamilia.

\section{MATERIALES Y MÉTODOS}

Se extrajeron inflorescencias de especimenes cultivados en el Jardín Botánico Universitario de Maracay, Facultad de Agronomía, Universidad Central de Venezuela (FAGROUCV), de Copernicia tectorum (Guevara \& Lattke \# 95) y Washingtonia filifera (Guevara et al. \# 96) en diciembre de 2007; las exsiccatae fueron depositadas en el Herbario Víctor Manuel Badillo de la FAGRO-UCV (MY) y el Herbario Nacional de la Fundación Instituto Botánico de Venezuela (VEN).

La identificación de las especies se basó en las obras de Henderson et al. (1995) y Dransfield et al. (2008). De C. tectorum se recolectaron además, frutos en desarrollo. El material fue fijado en FAA ( $5 \%$ formaldehído puro, 5\% ácido acético puro, $90 \%$ etanol $70 \%$ ). Se registraron mediciones de las estructuras florales (longitud del pedicelo y cáliz; longitud y ancho de los botones florales preantéticos, filamentos, anteras y gineceo a nivel del ovario), utilizando 
15 flores por especie como se ha utilizado en el estudio de la estructura y desarrollo de inflorescencias en palmas (Ortega-Chávez \& Stauffer, 2011). Para estas mediciones las flores fueron diseccionadas, separándose las partes bajo un microscopio estereoscópico. Para las partes de mayor tamaño, se utilizó una regla graduada y para las de menor tamaño, una micro regla con 1división=0.1mm (\#TDI MRM100H - Micro Ruler), previamente utilizada en mediciones morfológicas (Salazar-Vallejo \& Buzhinskaja, 2013). Estos implementos se colocaron de manera paralela a cada una de las partes florales para tomar las medidas en milímetros. $\mathrm{La}$ terminología para la descripción de las partes florales fue tomada de Dransfield et al. (2008). Las flores enteras fijadas, fueron deshidratadas con alcohol butílico terciario, embebidas e incluidas en parafina, seccionadas transversal y longitudinalmente en forma seriada con un grosor de 6-7 $\mu \mathrm{m}$, utilizando un micrótomo de rotación; las secciones obtenidas fueron teñidas con safranina y fast green y montadas en bálsamo de Canadá, siguiendo el protocolo de Johansen (1940). Para esto se utilizaron seis flores y seis frutos por especie. Las secciones fueron observadas y analizadas en un microscopio óptico Nikon Eclipse E 200, realizándose descripciones de los tejidos epidérmico, fundamental y vascular desde la base hasta el ápice de cada estructura floral. Se obtuvieron fotografías mediante una cámara digital Evolution LC adaptada al microscopio. Estos procedimientos fueron realizados en el Laboratorio de Morfoanatomía Vegetal FAGRO-UCV.

\section{RESULTADOS}

C. tectorum: Flores hermafroditas, 1.5$2.3 \mathrm{~mm}$ de longitud y $1.4-2.3 \mathrm{~mm}$ de ancho, sésiles, subtendidas por una bráctea blanca, diminuta, perianto verde, engrosado y pubescente (Fig. 1A). Cáliz, tres lóbulos cortos, $1.5-1.9 \mathrm{~mm}$ de longitud. Corola, tres piezas unidas en la base, estivación valvada. Androceo, seis estambres adnados a la corola, filamentos fusionados formando un tubo con ápices libres redondeados y parte distal aguda de $0.25-0.4 \mathrm{~mm}$ de longitud; anteras dorsifijas de $0.25-0.4 \mathrm{~mm}$ de longitud y $0.2-0.3 \mathrm{~mm}$ de ancho. Gineceo de $0.45-0.8 \mathrm{~mm}$ de longitud y $0.55-0.7 \mathrm{~mm}$ de ancho, con tres carpelos libres

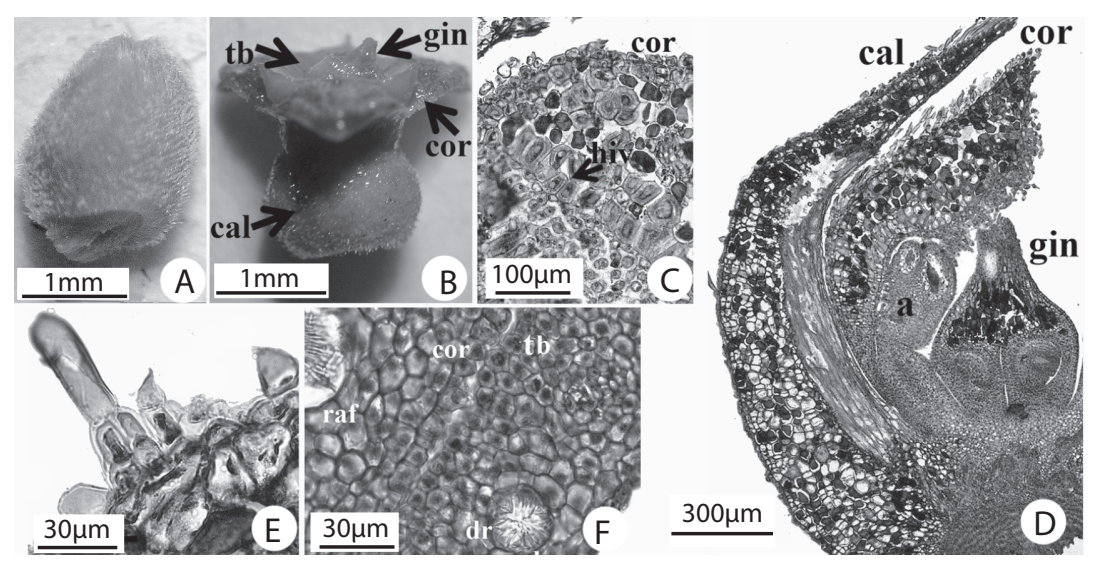

Fig. 1. Estructura floral de C. tectorum. A. Morfología del botón floral. B. Morfología del fruto en desarrollo temprano. C. Sección transversal del botón floral. D. Sección longitudinal de la porción media de la flor. E. Epidermis dorsal del cáliz con tricomas multicelulares. F. Idioblastos con drusa y rafidios. (a) androceo, (cal) cáliz, (cor) corola, (dr) drusa, (ev) epidermis ventral (gin) gineceo, (hiv) hipodermis ventral, (raf) rafidios, (tb) tubo estaminal.

Fig. 1. Floral structure of $C$. tectorum. A. Morphology of the floral bud. B. Morphology of the early developing fruit. C. Transverse section of the floral bud. D. Longitudinal section of the median portion of the flower. E. Dorsal epidermis of the calyx with multicelullar tricomes. F. Idioblasts with druse and raphids in the corolla. (a) androecium, (cal) calyx, (cor) corolla, (dr) druse, (ev) ventral epidermis (gin) gynoecium, (hid) dorsal hypodermis, (raf) raphides, (tb) staminal tube. 
hacia la base, unidos hacia el ápice, estilo corto indiviso (Fig. 1D). Anatomía. Cáliz: (Fig. 1C) Epidermis dorsal con células papilosas y tricomas de base uni o multiseriada, porción distal con una célula alargada (Fig. 1E). Células hipodérmicas dorsales cuadrangulares, de paredes ligeramente engrosadas. Haces vasculares ubicados ventralmente, con poco tejido vascular y esclerénquima asociado, alternando parénquima de células con paredes engrosadas. Células esclerenquimáticas con paredes más gruesas hacia el ápice. Corola: (Fig. 1C) Idioblastos con rafidios en toda su longitud (Fig. 1F). Epidermis dorsal como en los sépalos, tricomas desde el nivel medio hasta el ápice, la ventral también con tricomas (Fig. 1D). Epidermis dorsal como en los sépalos, tricomas sólo desde el nivel medio. Hipodermis ventral con células grandes, de paredes muy engrosadas homogéneamente. Pétalos con tres haces vasculares centrales hacia el ápice, de menor tamaño hacia la base. Androceo: (Fig. 1C y Fig. D) Exotecio y endotecio uniestratificados, con células de paredes delgadas. Una capa de células parietales estrechas. Tapete formado por una capa de células grandes. Sacos polínicos con células madres de las microsporas ovoides. Tejido conectivo con células vasculares poco diferenciadas. Tubo estaminal corto, ensanchado y plano hacia la base, con varios haces vasculares de pocas células conductoras. Idioblastos con drusas en el tejido conectivo y filamentos. Gineceo: (Fig. 1D y Fig. 2) Tres carpelos cerrados, libres, adpresos desde la base del ovario (Fig. 2A, Fig. B y Fig. F), uniéndose hacia la parte apical del mismo (Fig. 2D). Desde el ápice del ovario hasta el ápice del estilo, los carpelos están completamente unidos (Fig. 2D y Fig. E). Ápice del estilo con tres lóbulos unidos, sólido (Fig. 2E), el canal de transmisión tri-radiado central aparece cerca del ápice como tres ranuras separadas (Fig. 2D) que se unen más abajo (Fig. 2C). Se observan pocas células vasculares hacia el centro de la estructura. Entre el estilo y el ovario se encuentran células centrales afines a la tinción,

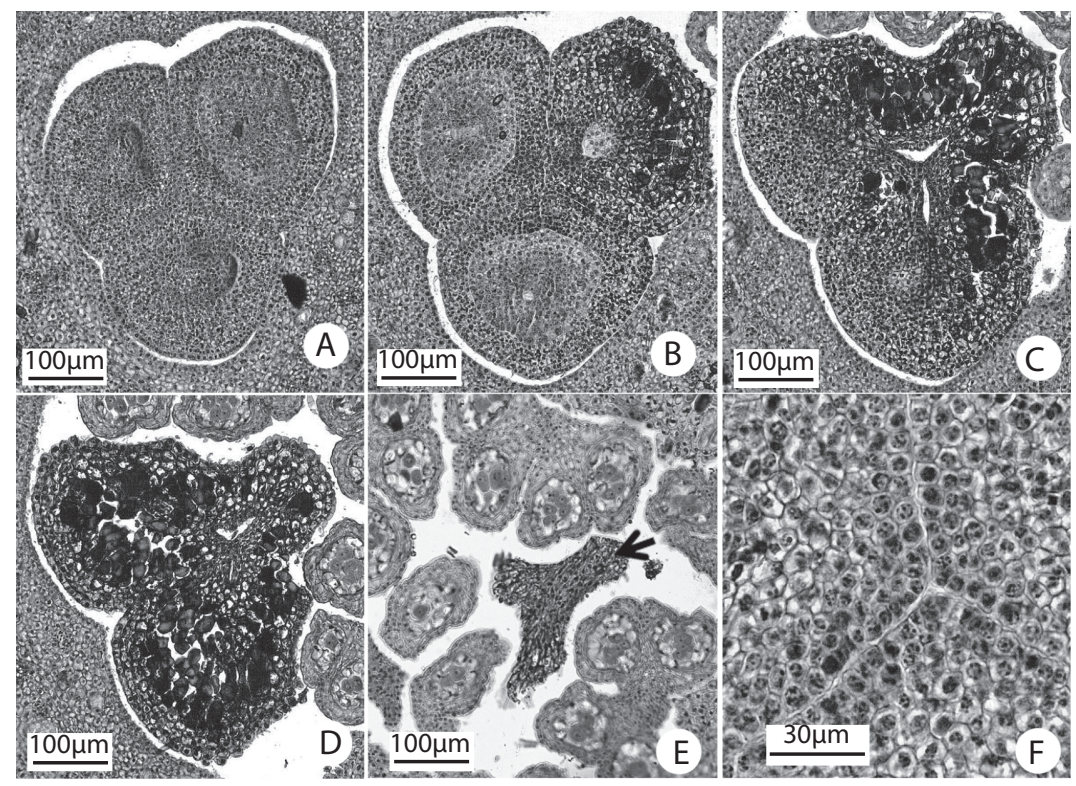

Fig. 2. Gineceo de C. tectorum. A-B. Región basal del ovario con apocarpía. C-D. Región apical del ovario con fusión postgenital de las paredes carpelares. E. Ápice del estigma (flecha). F. Detalle de la región ventral en los tres carpelos adpresos.

Fig. 2. Gynoecium of C. tectorum. A-B. Basal region of the ovary showing apocarpy. C-D. Apical region of the ovary showing postgenital fusion of carpel walls. E. Stigma apex (arrow). F. Detail of the ventral region in the three adpressed carpels. 
interpretadas como células con taninos (Fig. $2 \mathrm{C}$ y Fig. D). Óvulos: anátropos, placentación basal, redondeados. Fruto: (Fig. 1B y Fig. 3). Sólo un carpelo redondeado en desarrollo (Fig. 3B), células epidérmicas con paredes y cutícula engrosadas. Dos carpelos colapsados, observándose sólo los pedicelos (Fig. 3B). Cuatro regiones diferenciables en el mesofilo, de la epidermis dorsal a la ventral (Fig. 3C): 1) tejido con células parenquimáticas de gran tamaño y paredes engrosadas; 2) cuatro a cinco capas de parénquima; 3) parénquima con haces vasculares dispuestos en forma de un anillo discontinuo sin esclerénquima y abundantes idioblastos con taninos intercalados con rafidios; 4) tejido meristemático, hacia el límite del lóculo (células de menor tamaño, más vacuoladas, núcleos evidentes). Cavidad interna limitada por células epidérmicas cuadrangulares con paredes ligeramente engrosadas (Fig. 3C). Semilla: (Fig. 3A y Fig. B) redondeada en sección transversal, ovalada en sección longitudinal. Funículo corto.

W. filifera: Flores hermafroditas (Fig. 4A), subtendidas por una sola bráctea escamiforme, bífida con cada lóbulo dividido en dos, de apariencia delicada, blanco-crema, de 8.2$9.5 \mathrm{~mm}$ de longitud y $1.5-2.5 \mathrm{~mm}$ de ancho, pedicelo de $0.8-1.2 \mathrm{~mm}$ de longitud (Fig. 4B). Cáliz, tres piezas unidas en su base con borde irregularmente dentado, $3-3.7 \mathrm{~mm}$ de longitud, estivación imbricada. Corola, tres pétalos brevemente acuminados, imbricados, unidos en su base y a su vez parcialmente adnados al gineceo. Androceo, seis estambres, filamentos de $3.8-4.5 \mathrm{~mm}$ de longitud y $0.5-1 \mathrm{~mm}$ de ancho, unidos entre si en la base y adnados a la corola, engrosados hacia la base; anteras dorsifijas de $4.2-4.8 \mathrm{~mm}$ de longitud y $0.8-0.9 \mathrm{~mm}$ de ancho. Gineceo de 7.3-7.9mm de longitud y $0.2-0.3 \mathrm{~mm}$ de ancho, tres carpelos libres hacia la base, unidos hacia el ápice (Fig. 4A). Estilo

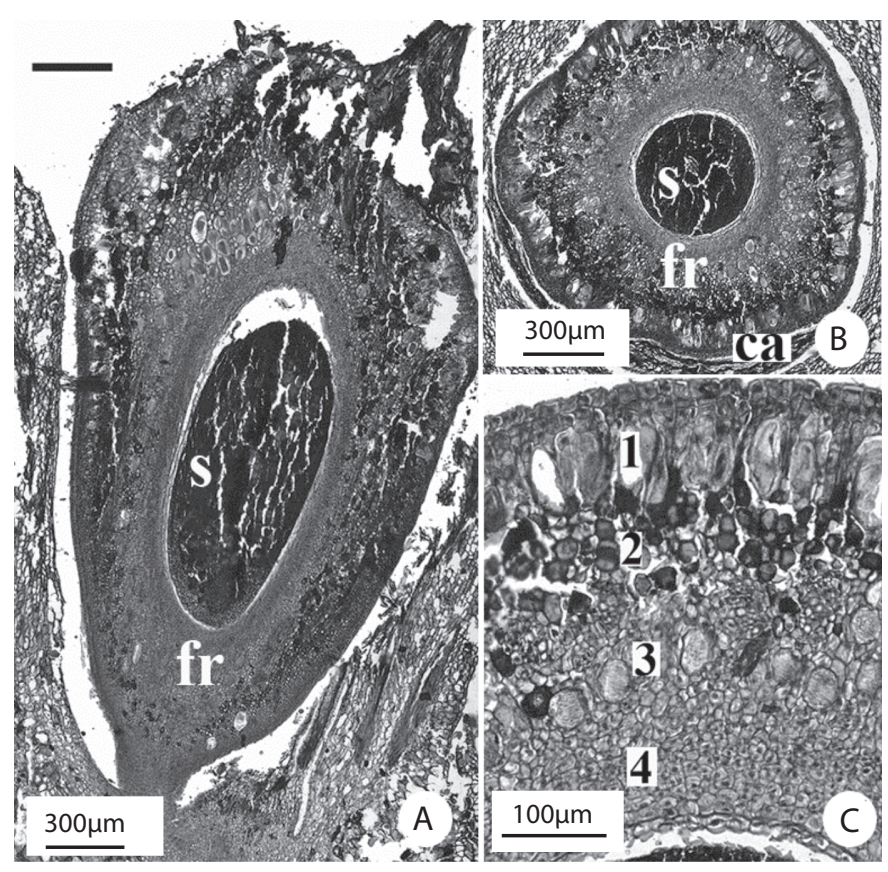

Fig. 3. Fruto en desarrollo de C. tectorum. A. Sección longitudinal. B. Sección transversal. C. Detalle de la sección transversal con distintas regiones histológicas. (fr) fruto, (s) semilla. (1) y (2) parénquima; (3) células con rafidios, (4) tejido meristemático.

Fig. 3. Developing fruit of C. tectorum. A. Longitudinal section. B. Transverse section. C. Details of the transverse section showing different histologic layers. (fr) fuit, (s) seed, (1) and (2) parenchyma; (3) cells with raphides, (4) meristematic tissue. 
alargado y delgado. Anatomía. Cáliz: (Fig. 4C) Epidermis dorsal, ventral y mesofilo con células de paredes engrosadas. Mesofilo con tejido esclerenquimático ventral. Pocos haces vasculares ubicados hacia la cara ventral, constituidos principalmente por xilema. Corola: (Fig. 4E) Conformación anatómica similar al cáliz. Células de los márgenes de los pétalos con paredes más engrosadas. Haces vasculares ubicados hacia la cara dorsal, con abundante tejido vascular y poco esclerénquima asociado. Androceo: (Fig. 4D) Anteras con exotecio uniestratificado de células papilosas y endotecio uniestratificado con engrosamientos en sus paredes. Granos de polen redondeados. Epidermis del tejido conectivo con células de pared externa convexa. Haz vascular central con células colapsadas. Filamentos engrosados hacia la base, delgados hacia el ápice, los antesépalos gruesos y los antepétalos delgados, con un solo haz vascular central sin esclerénquima asociado. Epidermis ventral papilosa hacia la base de los filamentos. Gineceo: (Fig. 4A y Fig. 5) Carpelos libres y cerrados en la base del ovario (Fig. 5A), unidos entre si un poco más arriba de la porción media de los lóculos (solo en la porción central) (Fig. 5B-Fig. 5. D) y gran parte del estilo (Fig. 5E), libres en la porción más apical del mismo, donde las suturas ventrales se encuentran abiertas (Fig. 5F). Los canales de transmisión estilares están separados en tres pequeñas ranuras (Fig. 5C) uniéndose desde la base del estilo hasta el ápice. Células epidérmicas de paredes engrosadas, cutícula ornamentada con ondulaciones hasta la porción media del estilo, engrosada, mesofilo con tres haces vasculares sin tejido esclerenquimático asociado. Ovario con epidermis de células alargadas radialmente y pared externa convexa en la base y en la porción media. Haces vasculares

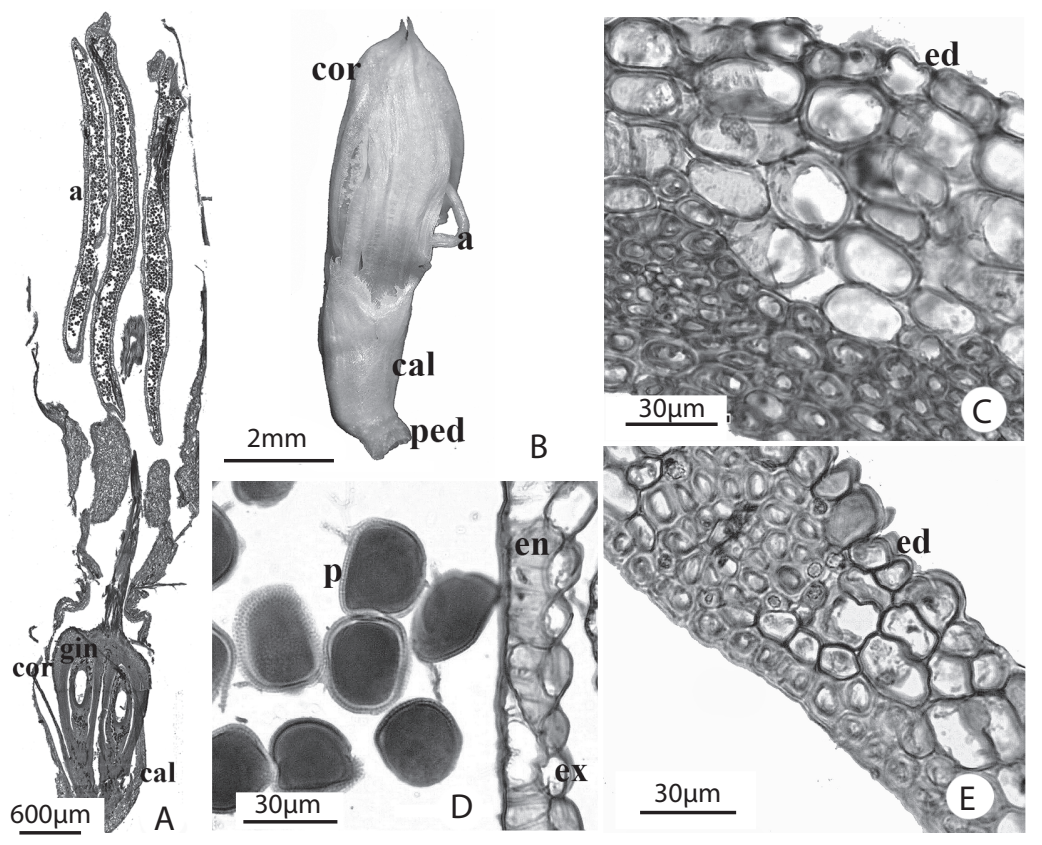

Fig. 4. Estructura floral preantética de $W$. filifera. A. Sección longitudinal. B. Morfología de la flor. C. Sección trasversal del cáliz en su porción media. D. Detalle de la sección transversal de una antera, saco polínico y granos de polen. E. Sección transversal de la corola en la región subapical. (a) androceo, (cal) cáliz, (cor) corola, (ed) epidermis dorsal, (en) endotecio; (ex) exotecio, (gin) gineceo, (p) granos de polen, (ped) pedicelo.

Fig. 4. Preanthetic floral structure of $W$. filifera. A. Longitudinal section. B. Morphology. C. Transverse section of the median portion of the calyx. D. Details of the transverse section of an anther, pollen sac and pollen grains. E. Transverse section of the subapical region of the corolla. (a) androecium, (cal) calyx, (cor) corolla, (ed) dorsal epidermis, (en) endothecium; (ex) exothecium, (gin) gynoecium, (p) polen grain, (ped) pedicel. 


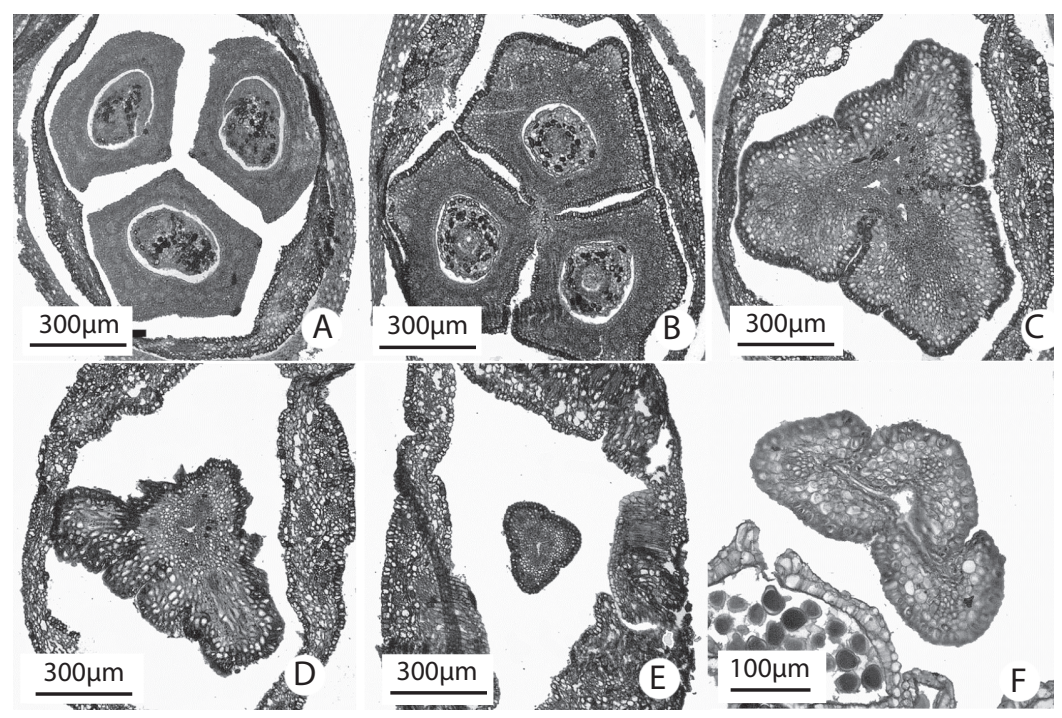

Fig. 5. Gineceo de W. filifera. A. Región basal del ovario con apocarpía completa. B-C. Región apical del ovario con transición entre apocarpía y syncarpía del tipo post-genital. D. Región basal del estilo. E. Región media del estilo. F. Región apical del estilo con suturas ventrales abiertas.

Fig. 5. Gynoecium of $W$. filifera. A. Basal region of the ovary showing complete apocarpy. B-C. Apical region of the ovary showing transition between apocarpy and post-genital syncarpy. D. Basal region of the style. E. Median region of the style. F. Apical region of the style, showing the open ventral suture.

formando un anillo discontinuo. Óvulos redondeados transversalmente, ovalados longitudinalmente, placentación basal, no fue posible observar el micrópilo. Funículo corto.

\section{DISCUSIÓN}

La morfología de las flores descrita coincide en líneas generales con lo indicado por Morrow (1965) y Dransfield et al. (2008); sin embargo, como pudimos demostrar, la fusión de los carpelos en $W$. filifera en la parte más distal del estigma no es completa; además, éstos permanecen unidos en una pequeña porción central desde casi la media altura de los lóculos hasta sus ápices, lo cual fue interpretado por Morrow (1965) como un estilo trilobado y carpelos fuertemente coherentes por encima de los ovarios. El gineceo de $C$. tectorum y $W$. filifera se incluye dentro de la agrupación propuesta por Rudall et al. (2011), gineceo tricarpelar con fusión carpelar distal. Estos autores estudiaron, entre otras especies a Copernicia x burretiana y pudieron observar evidencias de la fusión postgenital de los estilos, condición aparentemente única entre las monocotiledóneas. Las características anatómicas descritas confirman la afinidad de C. tectorum y $W$. filifera con la tribu Trachycarpeae, subtribu Livistoninae debido a que presentan canales estilares separados (C. tectorum) o sólo brevemente unidos distalmente ( $W$. filifera) (Dransfield et al., 2008) y a las similitudes con Licuala peltata en la fusión apical de los carpelos (Stauffer, Barfod, \& Endress, 2009; Rudall et al., 2011). La morfo-anatomía floral de Pritchardia presentada por Morrow (1965) y Dransfield et al. (2008) muestra similitudes con la flor de C. tectorum sobre todo en el cáliz con base carnosa, la morfología del androceo y la presencia de una hipodermis dorsal con células de paredes engrosadas en los pétalos.

En cuanto a $C$. tectorum, su gineceo se diferencia del de Trachycarpus fortunei (Uhl \& Moore, 1971), ya que éste presenta tricomas en las superficies carpelares, suturas ventrales 
abiertas, hipodermis y rafidios. Los apéndices en el perianto de flores en Arecaceae tales como tricomas y emergencias han sido poco detallados en la literatura, siendo reportados tricomas en el perianto en varios géneros de Trachycarpeae (Dransfield et al., 2008). Stauffer et al. (2009) encontraron tricomas unicelulares en la epidermis abaxial del cáliz y la corola de Licuala. En C. tectorum no habían sido reportados tricomas tectores multicelulares en el perianto. El botón de esta especie presenta poco tejido vascular y esclerénquima asociado en los haces vasculares, esta condición se mantiene en la flor fecundada-fruto analizado. Uhl y Moore (1977) correlacionan el tamaño de los haces vasculares con el tamaño del perianto en las especies de Coryphoideae estudiadas. A pesar de la poca cantidad de esclerénquima, la flor de esta especie muestra algunos tejidos para la protección del polen y óvulos, como una hipodermis ventral con células de paredes engrosadas y células con rafidios en los pétalos, drusas en los filamentos y células con acumulación de taninos por encima de los lóculos. Es importante destacar la presencia de abundantes drusas en los filamentos, los cuales no fueron reportados por Morrow (1965) para Copernicia macroglossa H. Wendl. ex Becc. ni para C. yarey Burret; por su parte, Uhl et al. (1969) encontraron escasos cristales en los sépalos y pétalos de Rhapis excelsa, sin indicar de qué tipo. De los tres carpelos completamente desarrollados, sólo uno culmina su crecimiento luego de la fecundación. El endocarpo del fruto de Copernicia se ha reportado como crustáceo (Dransfield et al., 2008), a pesar de lo temprano en desarrollo del fruto estudiado, es posible que la tercera capa señalada en los resultados, caracterizada por la presencia de células con rafidios, corresponda con el endocarpo del fruto maduro.

En W. filifera, el gineceo presenta suturas abiertas únicamente en la parte apical del estilo; esto coincide con las características del gineceo de Trachycarpus fortunei (Uhl \& Moore, 1971). El tejido vascular es escaso en todos los órganos florales; la vasculatura reducida en el perianto puede estar relacionada con el tamaño y forma del mismo en miembros de las Coryphoideae (Uhl \& Moore, 1977), menores cantidades de tejido podrían necesitar menor irrigación. En las flores de W. filifera, la escasa vascularización coincide con la poca cantidad de capas en el mesofilo del perianto. Además del tejido esclerenquimático asociado a los haces vasculares, el perianto está compuesto por células con paredes engrosadas que le confieren gran resistencia, a pesar de las pocas capas mesofilares. A diferencia de C. tectorum, $W$. filifera no presenta una hipodermis en el perianto; sin embargo, las células que conforman esta porción floral tienen paredes engrosadas, garantizando la protección al polen y óvulos. El gineceo y androceo tampoco presentan hipodermis pero tienen células esclerenquimáticas y con taninos, así como paredes celulares epidérmicas y cutícula engrosadas.

En conclusión, los resultados de este trabajo complementan la información sobre la estructura floral de dos especies de Trachycarpeae que hasta el momento no han podido ser ubicadas dentro de subtribus conocidas, apoyando la posibilidad de que Copernicia y Washingtonia sean incluidas dentro de la subtribu Livistoninae, basada en características morfoanatómicas de los canales estilares. Se describen caracteres anatómicos florales novedosos entre los cuales se destacan, la presencia de tricomas tectores multicelulares en el perianto y drusas en células de los filamentos de C. tectorum. Adicionalmente, los caracteres morfoanatómicos florales apoyan ciertas afinidades entre Copernicia y Pritchardia. Sin embargo, se hace necesario un estudio con mayor cantidad de especies para caracterizar los géneros, como siguiente paso para conseguir más evidencia en la búsqueda de la ubicación subtribal de estos géneros.

\section{AGRADECIMIENTOS}

Al Consejo de Desarrollo Científico y Humanístico-UCV por el financiamiento (PI 01-00-5781-2008). A los Bomberos Universitarios de la Facultad de Agronomía por su ayuda en la colección del material vegetal. A 
Norbelys Garcés por su asesoramiento en el procesamiento del material vegetal.

\section{RESUMEN}

Copernicia y Washingtonia son dos de los géneros de Trachycarpeae para los cuales no ha sido propuesta una clasificación subtribal debido a la carencia de resolución en los estudios filogenéticos. La morfología y anatomía floral dentro de Coryphoideae han sido útiles para la delimitación de taxones y apoyo de relaciones. En este trabajo se presenta una descripción de la estructura morfo-anatómica de las flores de C. tectorum y $W$. filifera, con la finalidad de explorar caracteres reproductivos que puedan aclarar su ubicación dentro de la subfamilia y contribuir con estudios de biología floral. Se fijaron flores de especimenes cultivados de ambos taxones y frutos en desarrollo de C. tectorum, se realizaron disecciones para las descripciones morfológicas y cortes anatómicos seriados para la obtención de láminas permanentes utilizando técnicas convencionales con parafina. Todos los procedimientos fueron llevados a cabo en el Laboratorio de Morfo-Anatomía, Facultad de Agronomía de la Universidad Central de Venezuela (UCV). Ambas especies tienen flores hermafroditas. Las flores de $C$. tectorum tienen perianto engrosado y pubescente. Las flores de $W$. filifera presentan un cáliz irregularmente dentado y corola corto-acuminada. Se reportan células con drusas en el tubo estaminal de C. tectorum. Uno solo de los carpelos de $C$. tectorum se desarrolla en fruto y se encontró una capa de células con rafidios que podrían formar el endocarpo crustáceo en los frutos maduros. W. filifera presenta pocas capas de células de paredes engrosadas y tejido esclerenquimático en el mesofilo del perianto, gineceo con carpelos fusionados en el ápice del ovario (en su porción ventral), libres en la base y en el ápice del estilo, donde presenta suturas ventrales abiertas. Los pétalos de $C$. tectorum poseen una hipodermis ventral de células con paredes muy engrosadas, gineceo con carpelos fusionados en el ápice del ovario, libres y adpresos en su base, región estilarestigmática fusionada y canal de transmisión estilar ausente distalmente. La presencia de canales estilares separados en C. tectorum, unidos distalmente en $W$. filifera confirman la relación cercana de estas especies con la subtribu Livistoninae. Igualmente, se encontraron algunas similitudes entre C. tectorum y Pritchardia (p.e. base carnosa del cáliz y epidermis ventral con células de paredes engrosadas en los pétalos), apoyando ciertas afinidades entre ambos géneros.

Palabras clave: anatomía, Arecaceae, Copernicia tectorum, flores, morfología, Trachycarpeae, Washingtonia filifera.

\section{REFERENCIAS}

Bacon, C. D., Baker, W. J., \& Simmons, M. P. (2012). Miocene dispersal drives island radiations in the palm tribe Trachycarpeae (Arecaceae). Systematic Biology, 61, 426-442.

Baker, W. J., Savolainen, V., Asmussen-Lange, C., Chase, M. W., Dransfield, J., Forrest, F., Harley, M. M., Uhl, N. W., \& Wilkinson, M. (2009). Complete generic-level phylogenetic analyses of palms (Arecaceae) with comparison of supertree and supermatrix approaches. Systematic Biology, 58, 240-256.

Baker, W. J., Dransfield, J., Harley, M. M., \& Bruneau, A. (1999). Morphology and cladistic analysis of subfamily Calamoideae (Palmae). In A. Henderson \& F. Borchsenius (Eds.), Evolution and classification of palms (Vol. 83, pp. 307-324). Memoirs of the New York Botanical Garden.

Castaño, F., Crèvecoeur, M., \& Stauffer, F. W. (2009). Contribution to the knowledge of the floral structure in Sabal palmetto (Walter) Lodd. ex Schult. (Arecaceae: Coryphoideae). Phytomorphology, 59, 85-91.

Castaño, F., Crèvecoeur, M., Pintaud, J. C., \& Stauffer, F. W. (2011). Floral structure in the Neotropical palm genera Chelyocarpus, Cryosophila and Itaya (Arecaceae: Coryphoideae). Candollea, 66, 65-80.

Dransfield, J., Uhl, N. W., Asmussen, C., Baker, W. J., Harley, M. M., \& Lewis, C. (2008). Genera Palmarum. Evolution and Classification of the palms. Londres: Kew Publishing.

Giddey, A., Spichiger, R., \& Stauffer, F. W. (2009). Comparative floral structure and systematics in the Asian palm genus Rhapis (Arecaceae, Coryphoideae). Flora, 204, 347-357.

Henderson, A., Galeano, G., \& Bernal, R. (1995). Field guide to the palms of Americas. Nueva Jersey: Princeton University Press.

Huber, O. \& Oliveira-Miranda, M. A. (2010). Ambientes terrestres de Venezuela. In J. P. Rodríguez, F. RojasSuárez, \& D. Giraldo Hernández (Eds.), Libro Rojo de los Ecosistemas Terrestres de Venezuela (pp. 29-89). Caracas: Provita, Shell y Lenovo.

Johansen, D. (1940). Plant microtechnique. Nueva Cork: McGraw-Hill.

Kahn, F. \& Gluchy, D. (2002). Variation in morphology of the pistillate flowers of Astrocaryum urostachis (Palmae) in Amazonian Ecuador. Nordic Journal of Botany, 22, 353-360. 
Morrow, L. O. (1965). Floral morphology and anatomy of certain Coryphoideae (Palmae) (Tesis doctoral). Cornell University, Nueva York.

Ortega-Chávez, N. \& Stauffer, F. W. (2011). Ontogeny and structure of the acervulate partial inflorescence in Hyophorbe lagenicaulis (Arecaceae; Arecoideae). Annals of Botany, 108, 1517-1527.

Rudall, P. J., Abranson, K., Dransfield, J., \& Baker, W. J. (2003). Floral anatomy in Dypsis (ArecaceaeAreceae): a case of complex synorganization and stamen reduction. Botanical Journal of the Linnean Society, 143, 115-133.

Rudall, P. J., Ryder, R. A., \& Baker, W. J. (2011). Comparative gynoecium estructure and multiple origins of apocarpy in coryphoid palms (Arecaceae). International Journal of Plant Sciences, 172, 674-690.

Salazar-Vallejo, S. I. \& Buzhinskaja, G. (2013). Six new deep-water sternaspid species (Annelida, Sternaspidae) from the Pacific Ocean. ZooKeys, 348, 1-27. doi: 10.3897/zookeys.348.544
Stauffer, F. W., Rutishauser, R., \& Endress, P. K. (2002). Morphology and development of the female flowers in Geonoma interrupta (Arecaceae). American Journal of Botany, 89, 220-229.

Stauffer, F. W. \& Endress, P. K. (2003). Comparative morphology of female flowers and systematics in Geonomeae (Arecaceae). Plant Systematics and Evolution, 242, 171-203.

Stauffer, F. W., Barfod, A., \& Endress, P. K. (2009). Floral structure in Licuala peltata (Arecaceae: Coryphoideae) with special reference to the architecture of the unusual labyrinthine nectary. Botanical Journal of the Linnean Society, 161, 67-77.

Uhl, N. W., Morrow, L. O., \& Moore, H. E. (1969). Anatomy of the palm Rhapis excelsa. VII. Flowers. Journal of the Arnold Arboretum, 50, 138-152.

Uhl, N. W. \& Moore, H. E. (1971). The palm gynoecium. American Journal of Botany, 58, 945-992.

Uhl, N. W. \& Moore, H. E. (1977). Correlation of inflorescence, flower structure, and floral anatomy with pollination in some palms. Biotropica, 9, 170-190. 